\title{
In Vitro Biopharmaceutical Equivalence of 5-mg Glibenclamide Tablets in Simulated Intestinal Fluid Without Enzymes
}

Angel T. Alvarado ${ }^{1 *}$, Ana Maria Muñoz ${ }^{2}$, Maria Bendezú3 ${ }^{3}$ Jorge A. García ${ }^{3}$, Juan J.

Palomino-Jhong ${ }^{3}$, Gaby Ochoa-Pachas ${ }^{4}$, Andres Chonn-Chang ${ }^{4}$, Luis Sullon-Dextre ${ }^{4}$, Berta Loja-Herrera ${ }^{4}$, and Mario Pineda-Perez ${ }^{4,5}$

${ }^{1}$ International Research Network in Pharmacology and Precision Medicine, Human Medicine School, San Ignacio de Loyola University, Lima, Peru.

${ }^{2}$ Research Unit in Nutrition, Health, Functional Foods and Nutraceuticals, Universidad San Ignacio de Loyola (UNUSAN-USIL), Lima, Peru.

${ }^{3}$ Faculty of Pharmacy and Biochemistry, National University San Luis Gonzaga, Ica, Peru.

${ }^{4}$ Peruvian Association of Immunogenomics and Personalized Medicine, Lima, Peru.

${ }^{5}$ Departmental Pharmaceutical Chemical College of Lima, Peru.

e-mail: eaa.alvarado@hotmail.com

\section{ABSTRACT}

This research evaluated the biopharmaceutical equivalence in vitro of three brands of glibenclamide 5-mg tablets (reference, brand name, and generic drugs) from Lima, Peru following the guidelines of the Biopharmaceutical Classification System (BCS). Glibenclamide is a BCS class 2 drug. Quality control parameters were evaluated including hardness, weight, friability, and drug content (hardness: $2.6-2.8 \mathrm{~kg}-f$; weight [mean $\pm \mathrm{SD}$ ]: 103.3-109.8 mg $\pm 0.27-0.53$; friability: $0.19-0.55 \%$; content: $100.65-103.3 \%)$. To assess dissolution, apparatus 2 was used at $75 \mathrm{rpm}, 900 \mathrm{~mL}$ of dissolution medium $\left(37 \pm 0.5^{\circ} \mathrm{C}\right)$ at $\mathrm{pH}$ 6.8; simulated intestinal fluid without enzymes was used as the dissolution medium. Samples $(5 \mathrm{~mL})$ were withdrawn at 5, 10, 15, 30, 45, 60, and 90 min and analyzed at $300 \mathrm{~nm}$ in a UV spectrophotometer. Dissolution percentages were $52.79-59.78 \%$ at 15 minutes, $59.78-64.54 \%$ at $30 \mathrm{mins}, 79.64-85.13 \%$ at $60 \mathrm{~min}$, and $98.33-99.92 \%$ at $90 \mathrm{~min}$. Based on the similarity factor $\left(f_{2}\right)$, the dissolution profiles of the brand name (66.61) and generic (70.10) drugs were considered similar to the reference drug (i.e., $f_{2}$ 50-100). Dissolution efficiency was greater than $70 \%$ and mean dissolution time exceeded 30 min $(p>0.05)$. According to the similarity factor and dissolution efficiency, the brand name and generic drugs are biopharmaceutical equivalents in vitro with the reference drug at $\mathrm{pH} \mathrm{6.8,} \mathrm{with} \mathrm{a}$ percentage difference < 5\%. However, glibenclamide tablets cannot be exempt from relative bioavailability studies because they did not release at least $85 \%$ of the drug within 30 minutes.

KEYWORDS: Glibenclamide, dissolution, generic drug, innovative drug, in vitro biopharmaceutical equivalence

\section{INTRODUCTION}

$\mathrm{n}$ emerging economy countries, such as Latin American countries, the use of generic drugs from multiple origins (multisource) is promoted. In Peru, the Supreme Decree on the interchangeability of drugs and the Ministerial Resolution of the list of drugs have been promulgated (1). Essential generic drugs have international non-proprietary names to allow for wide distribution of generic drugs from private and public pharmaceutical establishments (2-4). It is essential to have generic drugs to ensure access and availability of medicine in our country, but they must meet quality standards and be bioequivalent and 
interchangeable (4-6).

Bioequivalence studies for multisource drugs are essential to ensure that the active pharmaceutical ingredient (API) is available at the site of action (4). In vivo bioequivalence studies assess relative bioavailability (pharmacokinetic), pharmacodynamics, or therapeutic effectiveness and are performed for class 2 and 4 high health-risk drugs; in vitro bioequivalence studies are carried out for class 1 and 3 highly soluble drugs, according to the Biopharmaceutical Classification System (BCS) (7-10). Because glibenclamide is a class 2 drug with low aqueous solubility and high membrane permeability, it must be evaluated very rigorously through in vitro biopharmaceutical equivalence studies, including tests of weight, hardness, friability, content, disintegration, and dissolution (11-15).

To establish in vitro bioequivalence, various statistical models are applied, such as the difference factor $\left(f_{1}\right)$, which measures the percentage of error between two dissolution profiles at pre-established sampling times; if the result is zero, then the two profiles are considered equal, if $f_{1}$ is $0-15$, then the two profiles are similar, and if the $f_{1}$ is greater than 15 , then the profiles are different $(10,16,17)$. The similarity factor $\left(f_{2}\right)$, proposed by Moore and Flanner, measures the similarity between two dissolution curves (17-19). This factor is calculated from the mean percentage of dissolution at each sampling time $(9,10,17)$. If the result is 100 , the two dissolution profiles are identical, if $f_{2}$ is $50-100$, then the two profiles are considered to be similar, with some differences. For example, an $f_{2}$ value of 83.5 means that there is a difference of $2 \%, 65$ means the difference is $5 \%, 50$ means the difference is $10 \%, 41$ indicates a difference of $15 \%$, and 36 is a difference of $20 \%(8,20)$. Another parameter used to measure bioequivalence is dissolution efficiency (DE\%), which is the area under the dissolution curve at a predetermined time, expressed as a percentage of the rectangle described for $100 \%$ dissolution at the same time; the resulting value should optimally be $90 \%$ for immediate-release drugs, which indicates that rapid dissolution of the API occurs in the early stages of the dissolution profile $(9,10)$. Additionally, mean dissolution time (MDT) determines how fast the drug (solid form) dissolves in the dissolution medium $(9,10)$.

Glibenclamide is a second-generation sulfonylurea, used to treat type 2 diabetes. The chemical name is 5-Chloro- $\mathrm{N}$-[2-[4-(cyclohexylcarbamoylsulfamoyl) phenyl]ethyl]-2methoxybenzamide, and due to the sulfonamide group, it has a pKa of $5.3(14,21,22)$. Its low aqueous solubility is a limiting factor in dissolution, thus affecting its bioavailability, so the pharmacokinetic parameters are dependent on the formulation $(11,23,24)$. Glibenclamide is absorbed from the intestinal mucosa, observing a maximum plasma concentration $\left(C_{\max }\right)$ of $177 \pm 75 \mathrm{ng} / \mathrm{mL}$, the same that is reached in a maximum time $\left(t_{\max }\right)$ of 2-6 hours after ingestion of a single dose and fasting $(11,21,25)$. Food does not alter the rate of absorption in healthy volunteers (11). It is $99.8 \%$ bound to plasma proteins, especially albumin $(11,21)$. The drug's volume of distribution $(V d)$ is $9-10 \mathrm{~L}$, and its half-life time $\left(t^{1 / 2}\right)$ is $4-11$ hours (11). Glibenclamide is metabolized by phase I by the action of CYP2C9 and to a lesser extent by CYP3A4, transforming into two main active metabolites called 4-trans-hydroxycyclohexyl glibenclamide and 4-cis-hydroxycyclohexyl glibenclamide; the allelic variants CYP2C9*2, CYP2C9*3, and others should be considered in relative bioavailability studies, as they influence the therapeutic level and efficacy of glibenclamide $(21,26,27)$.

In Peru, counterfeit generic and brand-name drugs of dubious origin are marketed, as is the case in other low-income countries (28). Counterfeit drugs can have insufficient amounts or 
no API and counterfeit packaging, and generic drugs are questioned for low quality (29). This is a global public health problem, which is why the WHO has documented and analyzed that there are counterfeit drugs, substandard drugs, and unregistered or unlicensed medical products (30). It has been established that the largest production of bulk APIs for counterfeit drugs in the world are produced in China and India (31).

In Peru, quality control parameters of pharmaceutical products are regularly tested for compliance with specifications of the official pharmacopoeias, but there is still a need to analyze vitro biopharmaceutical equivalence via in vitro and in vivo bioequivalence studies. Therefore, it was decided to evaluate the glibenclamide tablets, which is a BCS class 2 drug included in the Ministry of Health's list of essential drugs, because they are available in the Peruvian pharmaceutical market and are considered low-quality drugs. The results of this study will form part of the scientific evidence to promote the implementation of bioequivalence studies, and with it, guarantee quality and interchangeable multisource drugs for the Peruvian population.

The objective of this research was to evaluate the in vitro biopharmaceutical equivalence between three glibenclamide $(5 \mathrm{mg}$ ) tablets prescribed in Lima, Peru (brand name, reference, and generic).

\section{METHODS AND MATERIALS}

\section{Chemicals and Reagents}

The reagents were analytical grade and American Chemical Society (ACS) quality, including $36 \%$ hydrochloric acid, sodium hydroxide, monobasic potassium phosphate, $50 \mathrm{mg}$ propylthiouracil tablets, and $96 \%$ ethanol. A United States Pharmacopeial (USP) glibenclamide standard was used. Chromafil syringe filters with a size of $25 \mathrm{~mm}$ and $0.45-$ $\mu \mathrm{m}$ pores were used. All substances and reagents were purchased from Mercantil SAC (Lima, Peru).

\section{Sample}

The sample size consisted of 200 glibenclamide 5-mg tablets from the brand name, reference, and one generic product. The brand name product, "Glibemlip-5" was assigned the letter " $M$ " (lot 183122039, RS No. EE-05288, expiration date 05/2021, Reyoung Pharmaceutical, Lipharma). The reference product, " $5 \mathrm{mg}$ Glidiabet," was assigned the letter "R" (lot 1010209, RS No. N-12347, expiration date 01/2022; Albis, Ferrer International SA). The generic "glibenclamide 5 mg" was assigned the letter " $A$ " (lot 20297260, RS No. EN-04934, expiration date 08/2023; Farmindustria). All samples were acquired from the same pharmacy in Lima, Peru.

\section{Equipment Calibration and Technique Validation}

The dissolution method was validated with 50-mg propylthiouracil tablets by spectrophotometry at a wavelength of $300 \mathrm{~nm}$ to evaluate the parameters of specificity, linearity, precision, and influence of filtration. Specificity indicates that there is no interference from tablet excipients in the determination of the API (i.e., no absorbance of placebo is observed in the maximum absorbance zone of API). Linearity was carried out in the range of $1.60-7.75 \mu \mathrm{g} / \mathrm{mL}$ with an $R^{2} 0.9998$. Precision was studied with six tablets on two different days, with no significant differences observed $(p=0.064)$. The test for influence of filtration showed that filtration does not adsorb the API and there is no interference $(p=0.32)$, so it is possible to use it in the experimental process. 
The dissolution equipment was calibrated, the same as performed once a year with USP prednisone tablets (disintegrating dissolution calibrator) and with USP salicylic acid tablets (non-disintegrating dissolution calibrator), in degassed purified water and in phosphate buffer $0.05 \mathrm{M} \mathrm{pH} 7.40 \pm 0.05$ (degassed) at $37 \pm 0.5^{\circ} \mathrm{C}$ for $30 \mathrm{~min}$. The isothermal medium (water bath) was classified in two stages: operation and performance. In the operation stage, the operation of the switched on was verified; the temperature selector of the equipment was set at $37{ }^{\circ} \mathrm{C}$ to check the performance of the water bath, observing the distribution of heat from the water bath that heats distilled water in the external container and degassed purified water inside the glass until reaching and keeping the optimum temperature constant at $37 \pm 0.5^{\circ} \mathrm{C}$. The water bath equipment heated homogeneously by thermal convection of the water.

According to the internal calibration sheet of the UV/Vis spectrophotometer (Varian $5 O B I O)$, the equipment passed the diagnosis of photometric accuracy, linearity, noise, stability, diffuse light, and resolution.

\section{Hardness Test}

The hardness of each tablet was determined by selecting 20 tablets of each product at random using a durometer, with an acceptance limit of $6 \pm 2 \mathrm{kgf}(29,32)$.

\section{Weight Variation}

Twenty tablets of each product were selected at random, then each tablet was weighed individually on an analytical balance. The tablet complies with the test if not more than two individual weights deviate from the average weight by more than the $5 \%(29,33)$.

\section{Friability Test}

A Erweka TADR friabilizer was used for this test. Twenty tablets of each of each product were weighed and placed in the friabilizer drum at $25 \mathrm{rpm}$ for $4 \mathrm{~min}$ (100 times), then the tablets were dusted and weighed. The difference in the two weights was used to calculate the friability, using the following formula: friability $=[(I w-F w) / I w] \times 100 \%$ where $I W$ is the total initial weight of the tablets and $F w$ is the total final weight of the tablets. The tablet complies with the test according to USP-NF if the tablets loss less than $1 \%$ of their initial weight $(33,34)$.

\section{Assay}

The average weight of 20 glibenclamide 5-mg tablets was determined, then they were crushed to fine powder to weigh the equivalent of $3.5 \mathrm{mg}$ of glibenclamide. Next, the powder was transferred to a $50-\mathrm{mL}$ volumetric flask, and $30 \mathrm{~mL}$ of $96 \%$ ethanol was added. The flask was mixed and subjected to the action of ultrasound (UCP-10, Lab Companion) for $30 \mathrm{~min}$ and allowed to cool to room temperature. Then the volume was made up to $50 \mathrm{~mL}$ with $96 \%$ ethanol, obtaining a final concentration of $0.07 \mathrm{mg} / \mathrm{mL}$. Finally, it was filtered to read the absorbance in triplicate at a wavelength of $300 \mathrm{~nm}$ using ethanol as a blank.

\section{Dissolution Test}

To perform the dissolution test, 12 tablets of each glibenclamide formulation were placed in a USP dissolution apparatus 2 (paddle) for 90 minutes at $75 \mathrm{rpm}$ with $900 \mathrm{~mL}$ volume of dissolution medium (simulated intestinal fluid without enzymes, SIF) pH 6.8 at $37 \pm 0.5^{\circ} \mathrm{C}$.

The SIF dissolution medium was prepared by dissolving $27.22 \mathrm{~g}$ of monobasic potassium 
phosphate $\left(\mathrm{KH}_{2} \mathrm{PO}_{4}\right)$ in $250 \mathrm{~mL}$ of water, then diluting with water to $1000 \mathrm{~mL}$. The $\mathrm{pH}$ was adjusted to $\mathrm{pH} 6.8 \pm 0.1$ with a $0.2 \mathrm{~N}$ sodium hydroxide solution or $0.2 \mathrm{~N}$ hydrochloric acid (33).

Deaeration of the dissolution medium was carried out under vacuum, passing the liquid through a $0.45-\mu \mathrm{m}$ membrane filter while sonicating with an ultrasound water bath (UCP10). The dissolver was programmed so that the dissolution medium took the optimum temperature. Each tablet was weighed and subsequently placed in each of the six containers containing $900 \mathrm{~mL}$ of dissolution medium.

The 5-mL samples were extracted through syringes with $0.45-\mu \mathrm{m}$ chromafil filters at 5,10 , $15,30,45,60$, and 90 minutes, without replacement of medium. These samples were covered with aluminum foil until analysis.

The absorbances were determined by UV/Vis spectrophotometry at a wavelength of 300 $\mathrm{nm}$, and dissolution medium $\mathrm{pH} 6.8$ was used as a blank. A calibration curve with an $R^{2}$ value of 0.9978 was made to calculate the concentration and percentage of content (4).

\section{Statistical Analysis}

SPSS 23 and Microsoft Office Excel 2007 were used for statistical analysis. As a statistical indicator of the in vitro biopharmaceutical equivalence, $f_{2}, \mathrm{DE} \%$, and MDT were used (10, 35). $\mathrm{DE} \%$ was determined with the formula: $\mathrm{DE} \%=(\mathrm{AUC}$ ot $\times 100) / Q \infty \times t \infty$, where AUCot is the area under the release curve from the initial time to the final time of the experiment; $Q \infty$ is the mean amount of drug obtained at the end time $(t \infty)$ of the experiment. MDT was estimated with the formula: MDT $=\sum$ iti $\Delta Q . t i / Q \infty$, where $\sum i t i \Delta Q . t i$ is the sum of the intermediate times $(t i)$ and the increase in the dissolved amounts of dissolved drug ( $\Delta Q . t i)$ $(9,10,35)$. A one-way analysis of variance (ANOVA) was performed, and Tukey and Dunnett were determined as a multiple comparison test (reference versus the brand name and generic products). A value of $p<0.05$ was considered significant $(9,35)$.

\section{RESULTS}

The results showed that the investigated brands had a hardness value within the acceptable range of $6 \pm 2 \mathrm{kgf}$ (2.6-2.8 kgf); mean weights had a standard deviation of less than $5 \%$ (103.3-109.8 mg, SD $\pm 0.27-0.53$ ). Similarly, the percentage of weight loss of the tablets after the friability test was acceptable $(0.19-0.55 \%)$, and the percentage of drug content was within the declared amount (100.65-103.30\%) (Table 1).

The investigated drugs did not meet the dissolution criteria at 15, 30, and $45 \mathrm{~min}$. At 60 min, only the reference product dissolved more than $85 \%$ in the SIF dissolution medium. There were no statistically significant differences $(p>0.05)$ (Table 2).

Table 3 shows the dissolution percentages of the 5-mg glibenclamide tablets, previously studied in other countries such as Ethiopia, Cuba, and Guatemala, observing dissolution percentages lower than $85 \%$ up to 120 min, except for generic drugs in Guatemala, which reached $85 \%$ dissolution after $60 \mathrm{~min}$, but standard deviation values were not reported. These studies indicate that the first phase of the dissolution process is slow and variable.

Figure 1 shows the dissolution profiles of 5-mg glibenclamide for the brand name and generic products, indicating a slow curve up to $30 \mathrm{~min}$ and more than $75 \%$ dissolving after $45 \mathrm{~min}$. When compared to the reference, similarity factor values $\left(f_{2}\right)$ were 66.61 for the brand name and 70.10 for the generic product. 
Table 1. Quality Control Characteristics of Glibenclamide 5-mg Tablets

\begin{tabular}{|c|c|c|c|c|c|c|}
\hline & \multicolumn{2}{|c|}{$\begin{array}{c}\text { Hardness } \\
\text { (kgf) }\end{array}$} & \multicolumn{2}{c|}{ Weight Variation (mg) } & \multirow{2}{*}{$\begin{array}{c}\text { Friability } \\
\text { (\%) }\end{array}$} & Content (\%) \\
\cline { 2 - 5 } & Mean \pm SD & CV\% & Mean \pm SD & CV\% & & \\
\hline Ref & $2.803 \pm 0.052$ & 1.873 & $105.4 \pm 0.274$ & 0.260 & 0.19 & 100.65 \\
\hline Gen M & $2.670 \pm 0.145$ & 5.447 & $109.8 \pm 0.319$ & 0.290 & 0.55 & 103.30 \\
\hline Gen A & $2.610 \pm 0.055$ & 2.116 & $103.3 \pm 0.527$ & 0.510 & 0.49 & 101.50 \\
\hline
\end{tabular}

Ref: Reference (Lot no. 1010209, expires 01/22, Albis); Gen M: Lot no. 183122039, expires 05/21, Reyoung); Gen A: Lot no. 20297260, expires 08.23, Farmindustria; SD: standard deviation; CV\%: coefficient of variation.

Table 2. Dissolution Test Results for Glibenclamide 5-mg Tablets in SIF

\begin{tabular}{|c|c|c|c|c|c|c|c|c|c|c|c|}
\hline \multirow{2}{*}{$\begin{array}{l}\text { Time } \\
(\min )\end{array}$} & \multicolumn{3}{|c|}{ Reference } & \multicolumn{3}{|c|}{ Gen M } & \multicolumn{3}{|c|}{ Gen A } & \multirow{2}{*}{$\begin{array}{c}\text { ANOVA } \\
(p<0.05)\end{array}$} & \multirow{2}{*}{$\begin{array}{c}\begin{array}{c}\text { Dunnett / } \\
\text { Tukey }\end{array} \\
(p<0.05)\end{array}$} \\
\hline & $\begin{array}{c}\text { Mean } \\
\text { (\%) }\end{array}$ & $\begin{array}{c} \pm \\
\text { SD }\end{array}$ & CV\% & $\begin{array}{c}\text { Mean } \\
\text { (\%) }\end{array}$ & $\begin{array}{c} \pm \\
\text { SD }\end{array}$ & CV\% & $\begin{array}{c}\text { Mean } \\
\text { (\%) }\end{array}$ & $\begin{array}{c} \pm \\
\text { SD }\end{array}$ & CV\% & & \\
\hline 5 & 32.31 & 4.73 & 14.65 & 40.93 & 0.20 & 0.50 & 30.00 & 0.64 & 2.14 & 0.9695 & Ref vs Gen \\
\hline 10 & 48.58 & 1.63 & 3.36 & 46.92 & 0.96 & 2.04 & 49.51 & 0.28 & 0.57 & & M: \\
\hline 15 & 59.78 & 1.05 & 1.75 & 54.34 & 0.25 & 0.46 & 52.79 & 0.27 & 0.52 & & 0.9457 \\
\hline 30 & 64.54 & 0.23 & 0.35 & 61.51 & 0.31 & 0.51 & 59.78 & 1.05 & 1.75 & & \\
\hline 45 & 75.47 & 0.20 & 0.27 & 77.16 & 0.92 & 1.19 & 75.47 & 0.20 & 0.27 & & Ref vs Gen \\
\hline 60 & 85.13 & 0.11 & 0.13 & 79.64 & 0.00 & 0.00 & 79.78 & 0.52 & 0.65 & & \\
\hline 90 & 99.92 & 0.63 & 0.63 & 98.61 & 0.41 & 0.41 & 98.33 & 0.17 & 0.17 & & 2.867 \\
\hline
\end{tabular}

SIF: Simulated intestinal fluid without enzymes; Gen: generic; SD: standard deviation; CV\%: coefficient of variation; ANOVA: analysis of variance.

Table 3. Dissolution Test Results for Glibenclamide 5-mg Tablets from Previous Studies

\begin{tabular}{|c|c|c|c|c|c|c|c|c|}
\hline \multirow[t]{2}{*}{$\begin{array}{l}\text { Time } \\
(\min )\end{array}$} & \multirow{2}{*}{$\begin{array}{c}\text { Peru } \\
\text { Glidiabet }\end{array}$} & \multicolumn{2}{|c|}{$\begin{array}{c}\text { Ethiopia } \\
\text { Kassahun et al. (4) }\end{array}$} & \multicolumn{3}{|c|}{$\begin{array}{c}\text { Cuba } \\
\text { Pereda and Martínez (38) }\end{array}$} & \multicolumn{2}{|c|}{$\begin{array}{l}\text { Guatemala } \\
\text { Mansilla (39) }\end{array}$} \\
\hline & & Daonil & Melix & Daonil & $\begin{array}{c}\text { Gen } \\
\text { (Lot 8124) }\end{array}$ & $\begin{array}{c}\text { Gen } \\
\text { (Lot 8125) }\end{array}$ & Ref & $\begin{array}{l}\text { Gen } \\
\text { (EF2) }\end{array}$ \\
\hline 5 & $\begin{array}{l}32.31 \pm \\
4.73\end{array}$ & & & $\begin{array}{c}25.0 \pm \\
1.5\end{array}$ & $12.6 \pm 1.4$ & $14.0 \pm 0.7$ & & \\
\hline 10 & $\begin{array}{c}48.58 \pm \\
1.63\end{array}$ & $\begin{array}{c}51.89 \pm \\
0.028\end{array}$ & $\begin{array}{c}44.94 \pm \\
0.04\end{array}$ & $\begin{array}{c}33.1 \pm \\
0.8\end{array}$ & $18.3 \pm 1.3$ & $19.8 \pm 0.9$ & & \\
\hline 15 & $\begin{array}{l}59.78 \pm \\
1.05 \\
\end{array}$ & & & & & & 59.09 & 47.05 \\
\hline 20 & & $\begin{array}{c}53.64 \pm \\
0.012\end{array}$ & $\begin{array}{l}54.85 \pm \\
0.006\end{array}$ & $\begin{array}{c}43.3 \pm \\
1.5\end{array}$ & $26.7 \pm 1.3$ & $27.0 \pm 0.8$ & & \\
\hline 30 & $\begin{array}{c}64.54 \pm \\
0.23 \\
\end{array}$ & $\begin{array}{c}56.79 \pm \\
0.06\end{array}$ & $\begin{array}{l}67.5 \pm \\
0.067 \\
\end{array}$ & $\begin{array}{c}50.9 \pm \\
1.3\end{array}$ & $32.3 \pm 1.3$ & $33.0 \pm 0.5$ & 83.16 & 74.33 \\
\hline 45 & $\begin{array}{l}75.47 \pm \\
0.20\end{array}$ & $\begin{array}{c}60.69 \pm \\
0.02\end{array}$ & $\begin{array}{c}70.13 \pm \\
0.04\end{array}$ & $\begin{array}{c}57.2 \pm \\
1.5\end{array}$ & $39.1 \pm 1.4$ & $38.5 \pm 0.5$ & 94.90 & 83.92 \\
\hline 60 & $\begin{array}{c}85.13 \pm \\
0.11 \\
\end{array}$ & $\begin{array}{c}61.57 \pm \\
0.072 \\
\end{array}$ & $\begin{array}{c}73.16 \pm \\
0.035 \\
\end{array}$ & $\begin{array}{c}65.2 \pm \\
1.7 \\
\end{array}$ & $43.9 \pm 1.6$ & $43.4 \pm 0.6$ & 100.07 & 91.30 \\
\hline 90 & $\begin{array}{c}99.92 \pm \\
0.63\end{array}$ & & & & & & 102.92 & 95.73 \\
\hline 120 & & & & $\begin{array}{c}74.8 \pm \\
1.7\end{array}$ & $54.5 \pm 1.9$ & $54.5 \pm 1.0$ & & \\
\hline
\end{tabular}

Data are mean dissolution \% with standard deviation in parentheses.

Ref: reference; Gen: generic product. 
The AUC value for the reference drug was $6516.6 \mathrm{~min} \%$, followed by the brand name (6333.8 min\%) and generic (6224.3 min\%) drugs. All products had MDT values greater than $30 \mathrm{~min}$ (30.4-32.9 $\mathrm{min})$, and DE\% values were similar (70.33-72.47\%) (Table 4).

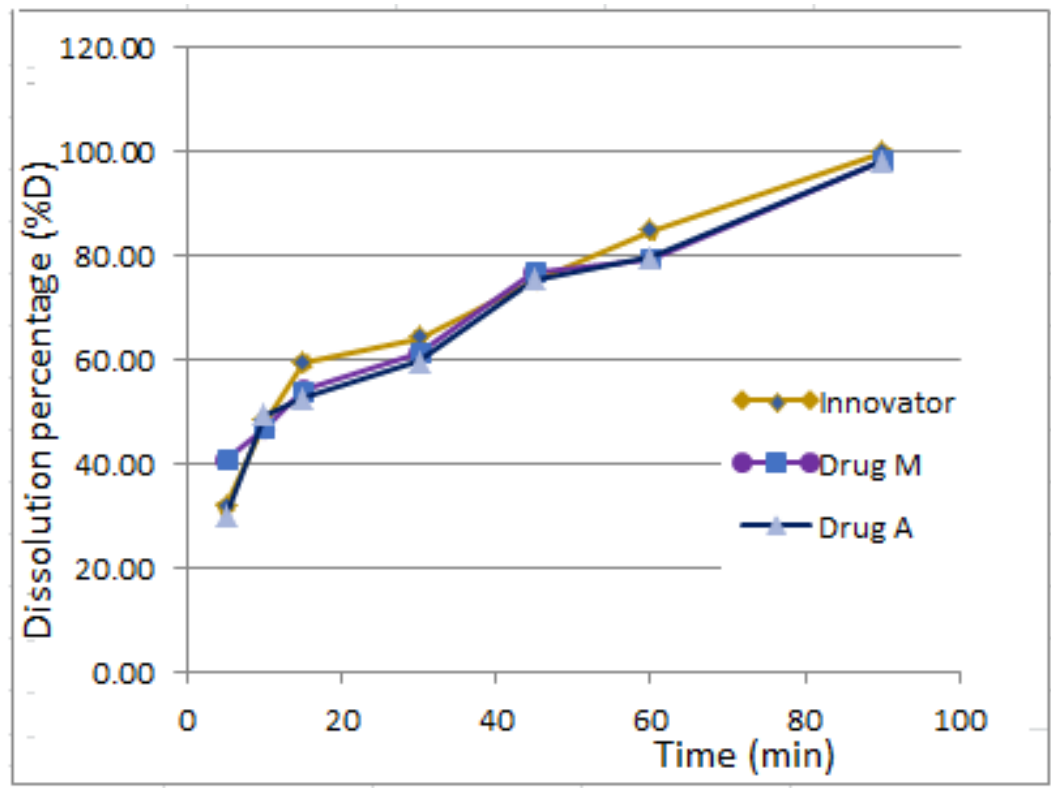

Figure 1. Dissolution profiles of 5-mg glibenclamide formulations in SIF.

Table 4. Parameters of the Drug Release Curve for Glibenclamide 5-mg Tablets at pH 6.8

\begin{tabular}{|c|c|c|c|c|}
\hline & $\begin{array}{c}\text { Similarity factor } \\
\left(\boldsymbol{f}_{2}\right)\end{array}$ & $\begin{array}{c}\text { AUC } \\
(\mathbf{m i n} \%)\end{array}$ & $\begin{array}{c}\text { MDT } \\
(\mathbf{m i n})\end{array}$ & $\begin{array}{c}\text { DE } \\
(\%)\end{array}$ \\
\hline Innovator & Ref & 6516.6 & 30.4 & 72.47 \\
\hline Generic M & 66.61 & 6333.8 & 32.0 & 71.37 \\
\hline Generic A & 70.10 & 6224.3 & 32.9 & 70.33 \\
\hline
\end{tabular}

$A U C$ : area under the release curve; MDT: mean dissolution time; DE: dissolution efficiency.

\section{DISCUSSION}

To demonstrate the bioequivalence of BCS class 2 drugs such as glibenclamide, the WHO and European Medicines Agency indicates to perform in vivo bioavailability studies $(7,8)$. Therefore, we conducted an in vitro biopharmaceutical equivalence study to evaluate the biopharmaceutical or drug release phase (disintegration, dissolution, and diffusion to the absorption site) of oral pharmaceutical forms based on the guidelines of the BCS that applies for class 1 and 3 (15). Our analyses included the hardness test, and results were below $6 \pm 2 \mathrm{kgf}$, which is the requirement of satisfactory hardness of a tablet $(29,32,34)$. Mean weights of the tablets had an SD less than $5 \%$, which ensures reproducibility within and between batches (36). Through the friability test, the resistance capacity of the tablets to abrasion was established. The results indicated that the surfaces of the tablets are fragile, but there were no cracked or broken tablets after performing the test. The content assay was within acceptable values (90-110\%) per USP specifications, which ensures the amount of API and is indicative of the efficacy and stability of the product $(9,33)$. The study confirmed that all three products of glibenclamide $5 \mathrm{mg}$ tablets investigated (reference, brand name, and generic) met the official quality control specifications.

The drug release phase was evaluated by the dissolution profile at seven sampling points, applying the same requirement criteria of class 1 , which indicates that very fast-acting 
drugs must dissolve at least $85 \%$ within $15 \min (7,8)$. As dissolution medium, we selected SIF pH 6.8, based on international literature and on three academic principles. The first indicates that glibenclamide has low aqueous solubility $\left(<0.004 \mathrm{mg} / \mathrm{mL}\right.$ at $\left.37^{\circ} \mathrm{C}\right)$ at low $\mathrm{pH}$ $(9,11,12,29)$; the second is to simulate an in vitro test with greater precision to the physiological conditions of the gastrointestinal tract, which allows predicting an optimal absorption of the drug in vivo (16); and the third is to exclusively simulate the physiological conditions of the small intestine, as it presents a large absorption surface that can reach $200 \mathrm{~m}^{2}$, so that all weak acidic or basic drugs are absorbed in this area. USP apparatus 2 was used at a speed of $75 \mathrm{rpm}$ to avoid the formation of cones, which can occur at a speed of $50 \mathrm{rpm}$ and affect the dissolution results $(7,8,37)$. The dissolution percentage found in this study was less than $85 \%$ at 15 minutes for the investigated drugs (Reference: $59.78 \%$, brand name: $54.34 \%$; generic: $52.79 \%$ ), indicating that it does not meet the standard ( $\geq$ $85 \%$ in $15 \mathrm{~min}$ ) (8). The coefficient of variation (CV) of the dissolution percentages obtained for the brand name and generic products was less than $2.14 \%$ up to $90 \mathrm{~min}$. This indicates that the criteria applied for class 1 drugs would be met (i.e., CV should not exceed $20 \%$ within the first $10 \mathrm{~min}$ and $10 \%$ at other time points) (8). There were no statistically significant differences in the dissolution profiles when the reference drug was compared with the brand name and generic drugs.

There are previous publications on the evaluation of the in vitro quality of generic glibenclamide 5-mg tablets reported in Ethiopia, Cuba, and Guatemala, observing that the dissolution profiles, as in our research, are slow. Kassahun et al. evaluated the quality and physicochemical bioequivalence of various brands of glibenclamide tablets marketed in Addis Ababa, Ethiopia using a dissolution medium at $\mathrm{pH} 7.4$ and reported $f_{2}$ values greater than 50 for all glibenclamide products (4). In contrast, Pereda and Martínez studied several batches of glibenclamide from the Medsol laboratory in Habana, Cuba in a dissolution medium at $\mathrm{pH} 7.6$ and reported $f_{2}$ values below 50 (i.e., similarity condition not met) (38). In Guatemala, Mansilla compared the dissolution profiles of generic glibenclamide in a dissolution medium at $\mathrm{pH} 7.5$ and reported three formulations with an $f_{2}$ greater than 50 , but four others were not bioequivalent in vitro (39). In another investigation carried out by El-Sabawi et al. in Jordan, five generic glibenclamide tablets were studied in a dissolution medium at $\mathrm{pH} 6.8$ and reported $f_{2}$ values below 50 (they did not publish dissolution percentages) (40).

In our research, rates of dissolution were slow in the first $30 \mathrm{~min}$, whereas in previously published studies, dissolution was slow up to $45 \mathrm{~min}$; this difference might be attributed to the drug's poor solubility in water, $\mathrm{pH}$ of the medium dissolution, technological process, and excipients. Silva Filho et al. and Mah et al. investigated various technological strategies to increase their solubility, proposing the use of molecular dispersion, micronization, and inclusion complexes with cyclodextrin and polymorphs $(14,41)$. Markopoulos et al. and Dressman et al. demonstrated that $\mathrm{pH}$ of the dissolution medium influences dissolution profiles $(16,42)$. Battu et al. demonstrated that technological processes (mixing time, compression force, and formulation) and the amount of disintegrant and lubricant influence the dissolution profile (43). All these factors can contribute to irregular and delayed absorption in vivo.

In the present study, the similarity factor indicated that the drug release curves of the brand name and generic drugs are similar to the reference at $\mathrm{pH} 6.8$ as evidenced $f_{2}$ values in the range of 50-100), with a less than $5 \%$ difference for the brand name $\left(f_{2}: 66.61\right)$ and 
generic $\left(f_{2}: 70.10\right)$. Additionally, DE\% values were higher than $63.2 \%$ (brand name: $71.37 \%$; generic: $70.33 \%$; reference: $72.47 \%$ ) (10). This parameter directly correlates with the degree of absorption of a drug in vivo, because when more than $63.2 \%$ of a tablet dissolves, it is ensured to be in the fluid when contact is made with the intestinal mucosa for absorption $(9,10)$. MDT was greater than $30 \mathrm{~min}$. When correlating MDT with mean gastric emptying (residence time), which under fasting conditions is 15-20 min, dissolution of the brand name and generic drugs is slow and variable within the first $30 \mathrm{~min}$.

One limitation of our study is the small sample size (only two brands were compared to the reference). We have not evaluated all generic and commercial brands of glibenclamide tablets available in the Peruvian pharmaceutical market. In addition, we did not perform the disintegration test, which should be considered in future studies. Notwithstanding the foregoing, this study provides scientific evidence for in vitro biopharmaceutical studies, which are required by regulatory agencies for approval of drugs like glibenclamide. These studies are needed to guarantee access to interchangeable medicines for patients with fewer economic resources and because the use of low-quality drugs can lead to reduced therapeutic efficacy or failure of treatment.

\section{CONCLUSIONS}

In conclusion, based on in vitro dissolution studies, applying $f_{2}$ and $\mathrm{DE} \%$, the glibenclamide $(5 \mathrm{mg}$ ) tablets investigated in this study are biopharmaceutical equivalents in vitro with the reference drug at $\mathrm{pH}$ 6.8. However, all three products did not meet criteria for very rapid dissolution (i.e., 85\% within 15 minutes). Therefore, glibenclamide tablets cannot be exonerated from relative bioavailability studies to demonstrate therapeutic equivalence and interchangeability in clinical practice.

\section{FUNDING}

This work was supported by the Peruvian Association of Immunogenomics and Personalized Medicine and the International Research Network in Pharmacology and Precision Medicine, Human Medicine School, of the San Ignacio de Loyola University, Lima, Peru.

\section{CONFLICTS OF INTEREST}

The authors disclosed no conflicts of interest related to this article.

\section{REFERENCES}

1. Regulation that regulates the interchangeability of medicines is approved [in Spanish]; Decreto supremo No. 024-2018-SA; MINSA. Sep 15, 2018. http://www.digemid.minsa.gob.pe/UpLoad/UpLoaded/PDF/Normatividad/2018/DS024-2018.pdf. (accessed July 19, 2020).

2. List of generic essential drugs in the International Common Denomination [in Spanish]. Resolución Ministerial No. 1097-2019/MINSA; MINSA. Nov 29, 2019. http://www.digemid.minsa.gob.pe/UpLoad/UpLoaded/PDF/Normatividad/2019/RM_1 097-2019-MINSA.pdf. (accessed July 19, 2020).

3. Raheela, B.; Gauhar, S.; Naqvi, B. S. Pharmaceutical evaluation of different brands of levofloxacin tablets $(250 \mathrm{mg}$ ) available in local market of Karachi (Pakistan). Int J Curr Pharm Res. 2011, 3, 15-22.

4. Kassahun, H.; Asres, K.; Ashenef, A. In Vitro and In Vivo Quality Evaluation of Glibenclamide Tablets Marketed in Addis Ababa, Ethiopia. J Pharm (Cairo). 2018, 2018, 
7916368. DOI: 10.1155/2018/7916368.

5. Hassali, M. A.; Thambyappa, J.; Saleem, F.; ul Haq, N.; Aljadhey, H. Generic substitution in Malaysia: recommendations from a systematic review. J. Appl. Pharm. Sci. 2012, 2, 159-164. DOI: 10.7324/JAPS.2012.2827.

6. Ngwuluka, N. C.; Lawal, K.; Olorunfemi, K. P. O.; Ochekpe, N. A. Post-market in vitro bioequivalence study of six brands of ciprofloxacin tablets/caplets in Jos, Nigeria. Sci. Res. Essays 2009, 4, 298-305.

7. WHO Expert Committee on Specifications for Pharmaceutical Preparations. Multisource (generic) pharmaceutical products: guidelines on registration requirements to establish interchangeability. WHO Technical Report Series, No. 1003, Annex 6; World Health Organization: Geneva, 2017.

8. ICH M9 Guidelines on Biopharmaceutics Classifcation System-Based Biowaivers; EMA/CHMP/ICH/493213/2018; Committee for Medicinal Products for Human Use (CHMP), European Medicines Agency: London, 2020.

9. Stuart, A. V.; Clement, Y.; Sealy, P.; Löbenberg, R.; Montane-Jaime, L.; Maharaj, R. G.; Maxwell, A. Comparing the dissolution profiles of seven metformin formulations in simulated intestinal fluid. Dissolut. Technol. 2015, 22, 17-21. DOI: 10.14227/DT220115P17.

10. Alvarado, A. T.; Muñoz, A. M.; Miyasato, J. M.; Alvarado, E. A.; Loja, B.; Villanueva, L.; Pineda, M.; Bendezú, M.; Palomino-Jhong, J. J.; García, J. A. In vitro therapeutic equivalence of two multisource (generic) formulations of sodium phenytoin (100 $\mathrm{mg}$ ) available in Peru. Dissolut. Technol. 2020, 27, 33-40. DOI: 10.14227/DT270420P33.

11. Pearson, J. G. Pharmacokinetics of glyburide. Am J Med. 1985, 79(3B), 67-71. DOI: 10.1016/S0002-9343(85)80010-3.

12. Dhillon, B.; Goyal, N. K.; Sharma, P. K. Formulation and evaluation of glibenclamide solid dispersion using different methods. Glob. J Pharmacol. 2014, 8, 551-556. DOI: 10.5829/idosi.gjp.2014.8.4.84283.

13. Wei, H.; Löbenberg, R. Biorelevant dissolution media as a predictive tool for glyburide a class II drug. Eur J Pharm Sci. 2006, 29, 45-52. DOI: 10.1016/j.ejps.2006.05.004.

14. Silva Filho, S. F.; Pereira, A. C.; Sarraguça, J. M. G.; Sarraguça, M. C.; Lopes, J.; Façanha Filho, P. F.; Dos Santos, A. O.; da Silva Ribeiro, P. R. Synthesis of a glibenclamide cocrystal: full spectroscopic and thermal characterization. J. Pharm. Sci. 2018, 107, 1597-1604. DOI: 10.1016/j.xphs.2018.01.029.

15. Matiz, G. E.; Trujillo, M.; Pérez, D. A.; Baena, Y. In vitro evaluation of the interchangeability of different brands of diclofenac sodium tablets available in the Colombian market [in Spanish]. Biomédica. 2018, 38, 486-495. DOI: 10.7705/biomedica.v38i4.3988.

16. Markopoulos, C.; Andreas, C. J.; Vertzoni, M.; Dressman, J.; Reppas, C. In-vitro simulation of luminal conditions for evaluation of performance of oral drug products: Choosing the appropriate test media. Eur. J. Pharm. Biopharm. 2015, 93, 173-182. DOI: 10.1016/j.ejpb.2015.03.009.

17. Tabbakhian, M.; Hasanzadeh, F.; Tavakoli, N.; Jamshidian, Z. Dissolution enhancement of glibenclamide by solid dispersion: solvent evaporation versus a supercritical fluid-based solvent-antisolvent technique. Res Pharm. Sci. 2014, 9, 337-350.

18. Moore, J. W.; Flanner, H. H. Mathematical comparison of curves with an emphasis on in vitro dissolution profiles. Pharm. Technol. 1996, 20, 64-74.

19. Costa, P.; Sousa Lobo, J. M. Influence of dissolution medium agitation on release profiles 
of sustained-release tablets. Drug Dev. Ind. Pharm. 2001, 27, 811-817. DOI:10.1081/DDC-100107244.

20. Mahesh Kumar, K.; Anil, B. Biopharmaceutics drug disposition classification system: An extensión of Biopharmaceutics Classification System. Int. Res. J. Pharm. 2012, 3, 5-10.

21. Malek, R.; Davis, S. N. Pharmacokinetics, efficacy and safety of glyburide for treatment of gestational diabetes mellitus. Expert Opin Drug Metab Toxicol. 2016, 12, 691-699. DOI:10.1080/17425255.2016.1187131.

22. Feldman, J. M. Glyburide: a second-generation sulfonylurea hypoglycemic agent. History, chemistry, metabolism, pharmacokinetics, clinical use and adverse effects. Pharmacotherapy. 1985, 5, 43-62. DOI: 10.1002/j.1875-9114.1985.tb03404.x.

23. Al-Ajmi, M. F. The effect of fenugreek on the bioavailability of glibenclamide in normal beagle dogs. Afr. J. Pharm. Pharmacol. 2011, 5, 671-677. DOI: 10.5897/AJPP11.102.

24. Prendergast, B. D. Glyburide and glipizide, second-generation oral sulfonylurea hypoglycemic agents. Clin Pharm 1984, 3, 473-485.

25. Jaber, L. A.; Antal, E. J.; Slaughter, R. L.; Welshman, I. R. Comparison of pharmacokinetics and pharmacodynamics of short- and long-term glyburide therapy in NIDDM. Diabetes Care. 1994, 17, 1300-1306. DOI: 10.2337/diacare.17.11.1300.

26. Ravindran, S.; Zharikova, O. L.; Hill, R. A.; Nanovskaya, T. N.; Hankins, G. D.; Ahmed, M. S. Identification of glyburide metabolites formed by hepatic and placental microsomes of humans and baboons. Biochem Pharmacol. 2006, 72, 1730-1737. DOI: 10.1016/j.bcp.2006.08.024.

27. Alvarado, A. T.; Muñoz, A. M.; Loja, B.; Miyasato, J. M.; García, J. A.; Cerro, R. A.; Quiñones, L. A.; Varela, N. M. Study of the allelic variants CYP2C9*2 and CYP2C9*3 in samples of the Peruvian mestizo population. [In Spanish] Biomedica 2019, 39, 601-610. DOI: $10.7705 /$ biomedica.4636.

28. List of counterfeit products evaluation and their alerts - DIRIS [in Spanish]. Ministry of Health, General Directorate of Medicines, Supplies and Drugs. http://www.digemid.minsa.gob.pe/UpLoad/UpLoaded/PDF/ControlYVigilancia/Comerci ollegaal/ProductosFalsificados/Productos_falsificados_2019_Nacional_diris.pdf. (accessed October 1, 2020).

29. Uddin, M. S.; Mamun, A. A.; Hossain, M. S.; Asaduzzaman, M.; Sarwar, M. S.; Rashid, M.; Herrera-Calderon, $\mathrm{O}$. In vitro quality evaluation of leading brands of ciprofloxacin tablets available in Bangladesh. Notes BMC Res. 2017, 10, 185. DOI: 10.1186/s13104-017-2507y.

30. OMS. World System Surveillance and Monitoring of Quality Medical Products Substandard and Counterfeit [in Spanish]. World Health Orgnization. 2018. https://www.who.int/medicines/regulation/ssffc/publications/GSMS_report_SP.pdf. (accessed October 1, 2020).

31. Khan, A.; Ghilzai, N. Counterfeit and substandard quality of drugs: the need for an effective and stringent regulatory control in India and other developing countries. Indian J. Pharmacol. 2007, 39, 206-213.

32. Oishi, T. S.; Haque, A.; Dewan, I.; Ashraful Islam, S. M. Comparative in vitro dissolution study of some ciprofloxacin generic tablets under biowaiver conditions by RP-HPLC. Int. J. Pharm. Sci. Res. 2011, 2, 3129-3135. DOI: 10.13040/IJPSR.0975-8232.2(12).3129-35.

33. The United States Pharmacopeia and National Formulary USP 33-NF 28; The United States Pharmacopeial Convention, Inc.: Rockville, MD, 2010.

34. Uddin, M. S.; Mamun, A. A.; Tasnu, T.; Asaduzzaman, M. In-process and finished 
products quality control tests for pharmaceutical tablets according to pharmacopoeias. J. Chem. Pharm. Res. 2015, 7, 180-185.

35. Tarawneh, O. A; Madi, A. M.; Hamed, R.; Qirem, R.; Qerem, W.; Alhusban, A.; Sunoqrot, S.; Mahmoud, N.; Ata, S.; Alsheikh, I. In vitro characterization and evaluation of commercialized paracetamol products in Jordan. Dissolut. Technol. 2019, 26, 36-44. DOI: 10.14227/DT260119P36.

36. León, G.; Osorio, M.; Matiz, G. Estudio biofarmacéutico comparativo de tabletas de acetaminofén $500 \mathrm{mg}$ disponibles en el mercado colombiano. Rev. Cuba. Farm. 2015, 49, 630-640.

37. Higuchi, M.; Yoshihashi, Y.; Tarada, K.; Sugano, K. Minimum rotation speed to prevent coning phenomena in compendium paddle dissolution apparatus. Eur. J. Pharm. Sci. 2014, 65, 74-78. DOI: 10.1016/j.ejps.2014.09.010.

38. Rodriguez, D. P.; Martínez, L. M. DaonilÒ and glibenclamide $5 \mathrm{mg}$ of national production: in vitro release [in Spanish]. Rev. Cuba. Farm. 2007, 41.

39. Mansilla Cortez, W. R. Comparison of the kinetics of generic dissolution of national production glibenclamide to determine its similarity in biodavailability with regard to presentation original [in Spanish]. Thesis, Universidad de San Carlos de Guatemala. October 2006. http://biblioteca.usac.edu.gt/tesis/06/06_2367.pdf. (accessed July 31, 2020).

40. El-Sabawi, D.; Abbasi, S.; Alja'fari, S.; Hamdan, I. Pharmaceutical evaluation of glibenclamide products available in the Jordanian market. Afr. J. Pharm. Pharmacol. 2013, 7, 1464-1470. DOI: 10.5897/AJPP2012.0014.

41. Mah, P. T.; Laaksonen, T.; Rades, T.; Aaltonen, J.; Peltonen, L.; Strachan, C. J. Unravelling the relationship between degree of disorder and the dissolution behavior of milled glibenclamide. Mol Pharm. 2013, 11, 234-242.

42. Dressman, J. B.; Berardi, R. R.; Dermentzoglou, L. C.; Russell, T. L.; Schmaltz, S. P.; Barnett, J. L.; Jarvenpaa, K. M. Upper gastrointestinal (GI) pH in young, healthy men and women. Pharm. Res. 1990, 7, 756-761. DOI: 10.1023/A:1015827908309.

43. Battu, S. K.; Repka, M. A.; Majumdar, S.; Madhusudan, R. Y. Formulation and evaluation of rapidly disintegrating fenoverine tablets: effect of superdisintegrants. Drug Dev. Ind. Pharm. 2007, 33, 1225-1232. DOI: 10.1080/03639040701377888. 